F.F. Wirakusumah

R. Brand

J.B. Gravenhorst
A.K. Janmeja

B. Raj

N.K. Jhamb

B. Arora

E.A. Soepardi
A multivariate analysis of risk factors influencing the cesarean section rate in two university hospitals in Leiden (the Netherlands) and Bandung (Indonesia)

During ten year period the factors that played an important role in the decision to perform a cesarean section were more or less the same in two very different countries.

\section{Clinical trial of $\mathbf{4}$ month chemotherapy regimen in tuberculous pleural} Effusion

Four month short course chemotherapy consisting of 2 SHZR/2HR was succesful in the treatment of tuberculous pleural effusion.

Chest X-ray examination of aspirated peanut in children : is it important?

Chest X-ray examination is not suggested in aspirated peanut in children before 24 hours of lodgement.

The Editorial Board wishes to apologize for publishing the following article in the Medical Journal of Indonesia, vol. 6 \# 4, October-December 1997 edition.

"Food and social background of nasopharyngeal cancer patients in Jakarta" by A. Roezin.

This article is a duplication of an article written by the same author under the same title, published in the Asean Otolaryngology-Head and Neck Surgery Journal vol.1 \# 1, January-March 1997 edition. 